\title{
Mitotic and antiapoptotic effects of nanoparticles coencapsulating human VEGF and human angiopoietin-I on vascular endothelial cells
}

This article was published in the following Dove Press journal:

International Journal of Nanomedicine

23 May 2011

Number of times this article has been viewed

\author{
Afshan Afsar Khan \\ Arghya Paul \\ Sana Abbasi \\ Satya Prakash
}

Biomedical Technology and Cell Therapy Research Laboratory, Department of Biomedical Engineering Faculty of Medicine, McGill University Montreal, Québec, Canada
Correspondence: Satya Prakash Biomedical Technology and Cell Therapy Research Laboratory, Department of Biomedical Engineering and Artificial Cells and Organs Research Centre, Faculty of Medicine, McGill University, 3775 University Street, Montreal, Québec H3A 2B4, Canada

$\mathrm{Tel}+\mathrm{I} 5 \mid 43983676$

Fax +| $5|4398746|$

Email satya.prakash@mcgill.ca
Background: Research towards the application of nanoparticles as carrier vehicles for the delivery of therapeutic agents is increasingly gaining importance. The angiogenic growth factors, human vascular endothelial growth factor (VEGF) and human angiopoietin-1 are known to prevent vascular endothelial cell apoptosis and in fact to stimulate human vascular endothelial cell (HUVEC) proliferation. This paper aims to study the combined effect of these bioactive proteins coencapsulated in human serum albumin nanoparticles on HUVECs and to evaluate the potential application of this delivery system towards therapeutic angiogenesis.

Methods and results: The angiogenic proteins, human VEGF and human angiopoietin-1, were coencapsulated in albumin nanoparticles for better controlled delivery of the proteins. The application of a nanoparticle system enabled efficient and extended-release kinetics of the proteins. The size of the nanoparticles crosslinked with glutaraldehyde was $101.0 \pm 0.9 \mathrm{~nm}$ and the zeta potential was found to be $-18 \pm 2.9 \mathrm{mV}$. An optimal concentration of glutaraldehyde for the nanoparticle coating process was determined, and this provided stable and less toxic nanoparticles as protein carriers. The results of the study indicate that nanoparticles crosslinked with glutaraldehyde produced nanoparticles with tolerable toxicity which provided efficient and controlled release of the coencapsulated proteins. The nanoparticles were incubated for two weeks to determine the release profiles of the proteins. At the end of the two-week incubation period, it was observed that $49 \% \pm 1.3 \%$ of human angiopoietin- 1 and $59 \% \pm 2.1 \%$ of human VEGF had been released from the nanoparticles. The proliferation and percent apoptosis of the HUVECs in response to released proteins was observed.

Conclusion: The results indicate that the released proteins were biologically active and the combined application of both the proteins demonstrated a significant highly proliferative and antiapoptotic effect on HUVECs as compared with the effect demonstrated by the individual proteins released. These studies could serve as a basis to encourage further research into the potential in vivo application of these protein-loaded nanoparticles in the field of therapeutic angiogenesis.

Keywords: growth factors, encapsulation, nanoparticles, nanobiotechnology, angiogenesis, regenerative medicine

\section{Introduction}

Vasculogenesis and angiogenesis are the two essential mechanisms that implement the development of the vascular network. ${ }^{1,2}$ Vasculogenesis is a process in the early development of an individual during blood vessel network formation, whereas angiogenesis which is a similar process, does not occur only at the time of the creation but is a mechanism that occurs throughout the organism's life. Angiogenesis is basically associated with the proliferation, migration, and remodeling of fully differentiated 
endothelial cells and involves sprouting of new smaller blood vessels from pre-existing ones and repair of damaged blood vessels at the site of an injury. It is known that programmed cell death, ie, apoptosis, is required for normal development of multicellular organisms, whereby unwanted cells are eliminated during physiological and certain pathological conditions. ${ }^{3}$ However, it has also been shown that the dysregulation of endothelial cell apoptosis has a major regulatory effect on the establishment of the primordial vascular network, termed vasculogenesis in the embryo, causing severe hemorrhage and finally leading to embryonal death. Counteracting proliferation, endothelial cell apoptosis in excess may limit angiogenesis, thus leading to vessel regression. It is hence evident that inhibition of endothelial cell apoptosis can serve as a potential therapeutic target, especially in patients suffering from ischemic diseases for which prevention of apoptosis could improve angiogenesis and vasculogenesis.

Several growth factors and proteins have demonstrated an ability to prevent vascular endothelial cell apoptosis and in fact stimulate endothelial cell proliferation. Vascular endothelial growth factor (VEGF) is a mitogenic and chemotactic factor for endothelial cells, and seems to play a vital role in the protection of these cells against apoptosis. ${ }^{4-6}$ The use of human VEGF as a potential stimulant in therapeutic angiogenesis has been widely demonstrated. ${ }^{7-14}$ However, there is still an uncertainty as to whether the presence of human VEGF alone would suffice in the achievement of functional and mature vessels lined with vascular smooth muscles or pericytes. There is evidence that excessive human VEGF expression could bring about pathological and immature vessel formation and enhanced vascular wall permeability, and could lead to angioma formation. ${ }^{15-17}$ In this context, research has shown that the ligand of TIE-2 receptor, angiopoietin-1, has the ability to stabilize and assist in the maturation of blood vessels, ${ }^{18-20}$ and in fact abrogates endothelial cell apoptosis. ${ }^{21,22}$ However, there has been debate over the role of human angiopoietin-1 as an endothelial cell mitogen. While some studies have demonstrated human angiopoietin-1 to be a potent mitogen of endothelial cells, ${ }^{23}$ others have pointed out that human angiopoietin-1 either failed to induce proliferation, ${ }^{24}$ or did not cause a significant increase in the proliferation. ${ }^{25}$ However, on the whole, the administration of a combination of human angiopoietin-1 with human VEGF may prove to be an efficient strategy for therapeutic angiogenesis. Moreover, several studies have also demonstrated that the application of multiple growth factors for therapeutic applications has a greater impact than single growth factor delivery. ${ }^{26-28}$
Extensive research is being carried out to discover the potential of using recombinant proteins towards therapeutic applications. However, due to their very limited in vivo halflives, the proteins have to be administered through multiple injections to achieve the desired therapeutic effect. These macromolecules also have high molecular weights which lead to low bioavailability and high aqueous solubility, and they are incapable of diffusing through biological membranes. ${ }^{29,30}$ It is thus evident that appropriate delivery vehicles need to be developed for these macromolecules, which are in fact very unstable, so as to protect them from degradation in the biological environment of the organism. The potential to use these molecules for therapeutic applications greatly depends on the use of a suitable vehicle for delivery. Thus, numerous strategies have been applied towards the design of appropriate vehicles for efficient sustained growth factor delivery. ${ }^{31}$ However, the use of nanoparticles as protein delivery systems has gained interest. The use of nanoparticles has several advantages over microparticle encapsulation. ${ }^{32}$ By encapsulating the macromolecules, the physicochemical properties of the particles allow more controlled and continuous protein release over a period of several weeks.

Amongst the existing delivery systems, nanoparticles based on natural biopolymers have been shown to be very promising as compared with those made of synthetic materials. Albumin is a physiological protein that is found in abundance in the blood and can be purified easily. In our study, we made use of human serum albumin as the developing material for the delivery system. Human serum albumin has a molecular weight of $66 \mathrm{kDa}$ and has the ability to bind to hormones, long-chain fatty acids, metal ions with high affinity, and vitamins, thus serving as a transport and depot protein for a variety of compounds. ${ }^{33}$ Studies have also shown that human serum albumin binding results in decreased toxicity and an increase in the in vivo half-life of the bound ligands. ${ }^{34}$ In the literature, three methods exist for the preparation of human serum albumin-based nanoparticles based on emulsion formation, desolvation, or coacervation processes. ${ }^{35-37}$ In order to stabilize the resulting nanoparticles, glutaraldehyde can be used as the crosslinking agent. ${ }^{37,38}$ However, to date, the application of nanoparticles towards the encapsulation of growth factors is lacking. The objective of this study was to investigate the feasibility of entrapping the growth factors, human VEGF and human angiopoietin-1, in nanoparticles crosslinked with glutaraldehyde to enable potential application in therapeutic angiogenesis. 


\section{Materials and methods Materials}

Human serum albumin (fraction V, purity 96\%-99\%), bovine serum albumin, guanidine hydrochloride, and $8 \%$ glutaraldehyde were purchased from Sigma Aldrich (Oakville, ON, Canada). Human VEGF, human angiopoietin-1, and their respective enzyme-linked immunosorbent assay (ELISA) kits were purchased from R \& D systems (Minneapolis, MN), CellTiter $96^{\circledR}$ AQueous Non-Radioactive Cell Proliferation MTS Assay kit (Promega, Madison, WI) was used to detect cytotoxicity and cell proliferation. Antibodies against human VEGF and human angiopoietin-1 were purchased from Santa Cruz Biotechnology (Santa Cruz, CA).

\section{Cell culture}

Human vascular endothelial cells (HUVECs; Sciencell, Carlsbad, CA) were cultured and expanded on tissue culture plates according to the manufacturer's instructions. They were cultured in endothelial cell medium (Sciencell) supplemented with $5 \%(\mathrm{v} / \mathrm{v})$ fetal bovine albumin and placed in an incubator containing $5 \% \mathrm{CO}_{2}$ at $37^{\circ} \mathrm{C}$. The cells used in this study were from between passages 2 and 5 .

\section{Preparation of nanoparticles}

As demonstrated by our group earlier, human serum albumin nanoparticles were prepared using the $\mathrm{pH}$-coacervation technique..$^{39}$ Briefly, $100 \mathrm{mg}$ of human serum albumin protein was added to $2 \mathrm{~mL}$ of $10 \mathrm{mM} \mathrm{NaCl}$ solution in a glass vessel under constant stirring at room temperature. The $\mathrm{pH}$ was brought to 8 by the addition of $0.1 \mathrm{~N} \mathrm{NaOH}$. Then, $14 \mu \mathrm{L}$ of $0.5 \mathrm{mg} / \mathrm{mL}$ of human angiopoietin- $1,1 \mu \mathrm{L}$ of $0.5 \mathrm{mg} / \mathrm{mL}$ human VEGF, and $1 \mu \mathrm{L}$ of $0.5 \mathrm{mg} / \mathrm{mL}$ of bovine serum albumin dissolved in endothelial cell medium (with or without $5 \%$ fetal bovine albumin) was added into the above solution, and this aqueous phase was then desolvated with dropwise addition of ethanol $4 \mathrm{~mL}$ at a constant rate of $1 \mathrm{~mL} / \mathrm{min}$ to form the nanoparticles. The concentration of protein added during the nanoparticle preparation was optimized based on the fact that when the inhibitory doses of human angiopoietin-1 was almost 10 times more than those for human VEGF, both caused identical antiapoptotic effects in HUVECs and, using a combination of human angiopoietin-1 with human VEGF, produced a significantly greater antiapoptotic effect. ${ }^{22}$ Nanoparticles containing bovine serum albumin were taken as the negative control. The protein-encapsulated nanoparticles formed were then stabilized by coating with $40 \mu \mathrm{L}$ of $5 \%$ glutaraldehyde. The coated nanoparticles were purified by ultracentrifugation at 20,000 $\mathrm{g}$ for 15 minutes, and the pellet was redispersed into double-distilled $\mathrm{H}_{2} \mathrm{O}$ to original volume. The purification process was carried out three times, with each redispersion step performed in a Bransonic ${ }^{\circledR}$ Ultrasonic Cleaner 2510 bath (Branson, Danbury, CT) for 15 minutes. The entire procedure of particle preparation was carried out under sterile conditions, and all the solutions used during preparation were sterilized by passing them through $0.20 \mu \mathrm{m}$ sterile filters before use. The encapsulation efficiency of both the proteins was determined in terms of the amount of human angiopoietin-1 and human VEGF transformed into nanoparticles before coating using human angiopoietin-1 and human VEGF ELISA kits. The nanoparticles were centrifuged at 20,000 $\mathrm{g}$ for 15 minutes at room temperature to separate the nanoparticles from the supernatant. Percentage encapsulation efficiency was calculated as:

$\left(\frac{\text { initial amount of growth factor }- \text { growth factor amount in the supernatant }}{\text { initial amount of growth factor }}\right) \times 100$

\section{Particle size and zeta potential of nanoparticles}

The particle size, zeta potential, and polydispersity index of the nanoparticles was measured by the technique of electrophoretic laser Doppler anemometry using a Zeta Potential Analyzer (Brookhaven Instruments Corporation, Holtsville, NY). For zeta potential determination, $0.005 \mathrm{M}$ phosphate buffer with $\mathrm{pH} 7.0$ was used. The ZetaPlus Particle Sizer software (version 4.11; Brookhaven Instruments Corporation) was used to determine the size distribution of the nanoparticles and the Zeta Potential Analyzer Version 3.57 (Brookhaven Instruments Corporation) was the software used for the zeta potential. Both the particle size and the zeta potential were measured for three batches of nanoparticles, and each measurement was obtained after taking the average of the three runs.

\section{Nanoparticle surface characterization}

Scanning electron microscopy (SEM) was used to study the morphological characteristics of the nanoparticles. The nanoparticles were dispersed in double-distilled $\mathrm{H}_{2} \mathrm{O}$ and then dried with natural convection under room temperature. The samples were then examined under S4700 FEG-SEM (Hitachi, Oakville, Canada).

Transmission electron microscopy (TEM) was used to obtain the size characterization. The nanoparticles were suspended in $1 \times$ phosphate-buffered saline and analyzed on CM200 FEG-TEM (Philips, Markham, Canada). 
For the atomic force microscopy (AFM) measurements, the nanoparticle samples were sonicated for 5 minutes, and $1 \mu \mathrm{L}$ of the sample was dropped on to the surface of the discs and dried using the conventional method. Images were produced with Nanoscope III AFM (Digital Instruments, Palo Alto, CA) using silicon cantilever in tapping mode and analyzed using Nanoscope software (version 5.12r5; Digital Instruments).

\section{In vitro cytotoxicity of nanoparticles with MTS assay}

CellTiter 96 Aqueous Non-Radioactive Cell Proliferation MTS Assay kit (Promega) was used to assess the in vitro cytotoxicity of the various concentrations of glutaraldehyde on HUVECs. ${ }^{39}$ The HUVECs were seeded at a density of $2 \times 10^{4}$ cells/well in a 96-well plate in fresh medium. Twenty-four hours after seeding, the HUVECs were washed with phosphate-buffered saline and incubated with nanoparticles crosslinked with $40 \mu \mathrm{L}$ of $1.5 \%, 3 \%$, $4.5 \%, 6 \%$, and $7.5 \%$ and control nanoparticles without glutaraldehyde crosslinking for 96 hours. The relative HUVEC viability was determined by MTS assay, which was performed as per the manufacturer's protocol. Briefly, after 96 hours of incubation, the HUVECs were washed with phosphate-buffered saline and fresh endothelial cell medium was added to the wells. This was followed by the addition of $20 \mu \mathrm{L}$ of MTS solution to each well and the cells were incubated for four hours at $37^{\circ} \mathrm{C}$. The measurement of the absorbance was carried out using the 1420-040 Victor $3^{\mathrm{TM}}$ Multilabel Counter (Perkin Elmer, Woodbridge, Canada) at $490 \mathrm{~nm}$. An optimal concentration of glutaraldehyde was chosen to form the coating of the protein-loaded nanoparticles.

\section{In vitro release of coencapsulated human angiopoietin-I and human VEGF}

The protein-loaded nanoparticles were coated with $40 \mu \mathrm{L}$ of $5 \%$ glutaraldehyde for this study. The nanoparticles were incubated with $5 \mathrm{~mL}$ of endothelial cell medium with $1 \%$ penicillin/streptomycin at $37^{\circ} \mathrm{C}$ under constant shaking. The experiment was carried out in triplicate. The samples were then centrifuged at $20,000 \mathrm{~g}$ for 15 minutes at the indicated time points and $0.4 \mathrm{~mL}$ of supernatant was removed. In order to maintain a constant volume, the same amount of fresh endothelial cell medium was added back to the pellet. The amount of human angiopoietin-1 and human VEGF protein released into the supernatant was determined using human angiopoietin-1 and human VEGF ELISA kits, respectively, according to the manufacturers' protocols.

\section{HUVEC proliferation assay}

The bioactivity of released human VEGF and human angiopoietin-1 dissolved in endothelial cell medium (supplemented with $5 \%$ fetal bovine albumin) from the nanoparticles was evaluated in vitro by determining the proliferative capacity of the HUVECs. The CellTiter 96 Aqueous Non-Radioactive Cell Proliferation MTS Assay kit (Promega) was used to assess proliferation of the human vascular endothelial cells treated with nanoparticle supernatant. ${ }^{40,41}$ The HUVECs were plated in a density of $2 \times 10^{4}$ cells/well in a 96-well plate in endothelial cell medium containing $5 \%(\mathrm{v} / \mathrm{v})$ fetal bovine albumin. After 24 hours, the endothelial cell medium was removed and the cells were then incubated for 96 hours with $0.1 \mu \mathrm{L}$ of nanoparticle supernatant, nanoparticle supernatant with excess human VEGF antibody, and nanoparticle supernatant with excess human angiopoietin- 1 antibody released from the nanoparticles into the endothelial cell medium on days 2,8 , and 14. The results from the ELISA were used to determine the concentration of human angiopoietin-1 and human VEGF in the nanoparticle supernatant. Control samples received the same amount of endothelial cell medium (supplemented with $5 \%$ fetal bovine albumin) and nanoparticle supernatant with bovine serum albumin. The relative HUVEC viability was determined by MTS assay which was performed as per the manufacturer's protocol. Briefly, after 96 hours of incubation, the HUVECs were washed with phosphate-buffered saline, and fresh endothelial cell medium was added to the wells. This was followed by the addition of $20 \mu \mathrm{L}$ of MTS solution to each well, and the cells were incubated for four hours at $37^{\circ} \mathrm{C}$ The measurement of the absorbance was carried out using the $1420-040$ Victor $3^{\text {TM }}$ Multilabel Counter (Perkin Elmer) at $490 \mathrm{~nm}$.

\section{HUVEC apoptosis assay}

To determine the percentage apoptosis, nanoparticles were prepared using the same particle preparation protocol as before, but the proteins were dissolved in serum-free endothelial cell medium (without $5 \%$ fetal bovine albumin) instead of endothelial cell medium with 5\% fetal bovine albumin, and then added to the human serum albumin solution. The nanoparticles obtained were then incubated with $5 \mathrm{~mL}$ of serum-free endothelial cell medium with $1 \%$ penicillin-streptomycin at $37^{\circ} \mathrm{C}$, with constant shaking. 
The samples were then centrifuged at the indicated time points, and $0.4 \mathrm{~mL}$ of supernatant was removed. In order to maintain a constant volume, the same amount of fresh serum-free endothelial cell medium was added back to the pellet. The HUVECs were then seeded onto a 96-well plate at a cell density of $2 \times 10^{4}$ cells per well in endothelial cell medium supplemented with $5 \%$ fetal bovine serum and incubated at $37^{\circ} \mathrm{C}$ for 24 hours. After the incubation period, the cells were washed three times with phosphatebuffered saline, and the medium was replaced with $0.1 \mathrm{~mL}$ of nanoparticle supernatant, nanoparticle supernatant with excess human VEGF antibody, or nanoparticle supernatant with excess human angiopoietin-1 antibody from days 2 , 8 and 14, and incubated for 96 hours. Control cultures received the same amount of serum-free endothelial cell medium without the addition of human VEGF and human angiopoietin-1 proteins and nanoparticle supernatant containing bovine serum albumin. The numbers of cells floating in each well were collected after phosphate-buffered saline washing and counted. The number of apoptotic cells in the adherent cells was then determined after 96 hours using a MitoTracker ${ }^{\circledR}$ Red CMXRos kit and DAPI nucleic acid staining (Invitrogen, Burlington, Canada), according to the manufacturer's instructions, and were counted from random locations in the well using fluorescence microscopy. ${ }^{42}$ Both the staining techniques gave similar results and apoptosis was demonstrated as the percentage of apoptotic adherent cells and floating cells in a well. The experiment was carried out in triplicate.

\section{Results and discussion Characterization of nanoparticles}

In this study, the nanoparticles were prepared by a $\mathrm{pH}$ coacervation technique followed by glutaraldehyde crosslinking. Coacervation agents, such as ethanol, are widely used in protein purification processes, and nanoparticles are prepared by addition of coacervation agents to the protein solution. ${ }^{43}$ The nanoparticles were prepared by adjusting the $\mathrm{pH}$ of the human serum albumin solution to 8.0 and controlling the amount of coacervation agent to form nanoparticles of size $101.0 \pm 0.9 \mathrm{~nm}$, as shown in Figure 2A. It is known that the size of the resultant nanoparticles depends on the amount of the coacervation agent, but not on the amount of glutaraldehyde added or on the crosslinking procedure. ${ }^{37}$

The TEM, SEM, and AFM micrographs of the nanoparticles illustrated that the particles were properly dispersed, spherically-shaped, and had smooth surface characteristics, as shown in Figure 1. Figure 1A is a TEM image of the nanoparticles before ultrasonication, which indicates that, before ultrasonication, the nanoparticles form clusters and are not properly dispersed. Figure $1 \mathrm{~B}$ is the TEM image of the nanoparticles after ultrasonication for 15 minutes. Here it is demonstrated how ultrasonication assists in separating out the particles more uniformly and the particles are properly dispersed. Figure $1 \mathrm{C}$ gives the TEM image of the nanoparticles after magnification. Figure 1D is the SEM image for the nanoparticles crosslinked with $40 \mu \mathrm{L}$ of $5 \%(\mathrm{w} / \mathrm{v})$ glutaraldehyde which demonstrates the smooth surface characteristics of the nanoparticles. Figure 1E provides the three-dimensional AFM image of the nanoparticles.

The surface charge and size of the particles are the two main surface characteristics that influence the biodistribution of the nanoparticles upon administration. The zeta potential of the glutaraldehyde-crosslinked nanoparticles decreases when the concentration of glutaraldehyde is increased. ${ }^{37}$ Zeta potential measurements were performed in phosphate buffer at $\mathrm{pH} 7.0$ because the $\mathrm{pH}$ and ionic strength of the dilution medium affects the magnitude of the zeta potential. The value was found to be in accordance with the results shown by Lin et al. ${ }^{43}$ The protein nanoparticles were negatively charged and the zeta potential was $-18 \pm 2.9 \mathrm{mV}$ at $\mathrm{pH} 7.0$ as shown in Figure 2B. The polydispersity index was found to be 0.3 .

\section{Determination of cytotoxic effects of nanoparticles on HUVECs}

Glutaraldehyde has been widely used as a crosslinking agent in the preparation of nanoparticles. However, it is known to induce cytotoxicity, and higher concentrations of glutaraldehyde in particle preparation can lead to an increased toxicity to the cells. Therefore, an optimal amount of glutaraldehyde to be used in the particle preparation was determined for stable and less toxic nanoparticles. The cytotoxicity of the blank nanoparticles crosslinked with a series of glutaraldehyde concentrations was studied by incubating HUVECs for 96 hours with the nanoparticles. MTS assay was used to determine the percentage of viable cells compared with the initial number of cells. As shown in Figure 3, human serum albumin nanoparticles without glutaraldehyde coating showed a cell viability of above $90 \%$ after 96 hours. Increasing the concentration of glutaraldehyde in the particle preparation increased the cytotoxicity of the nanoparticles to the seeded 

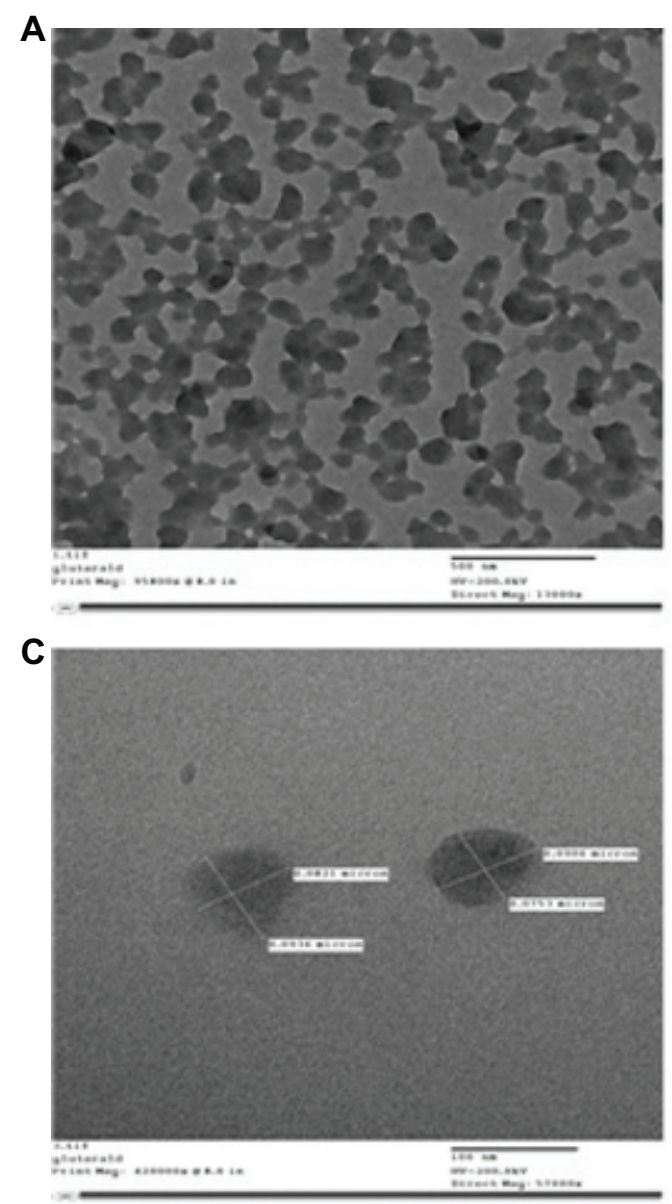
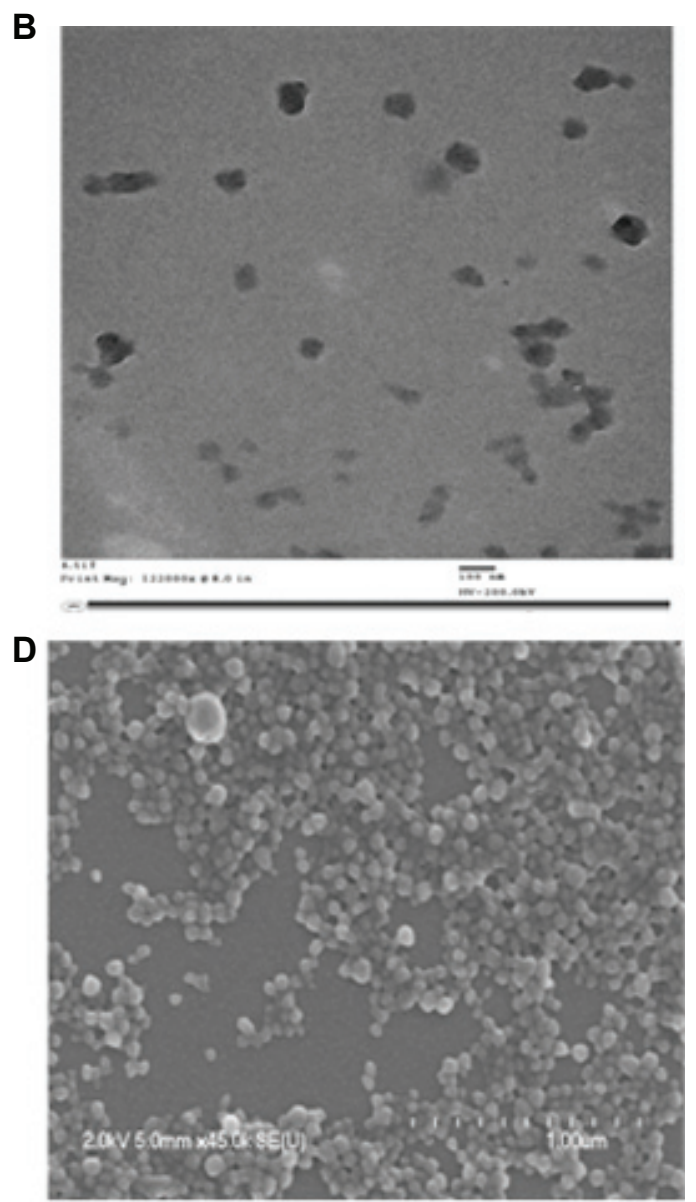

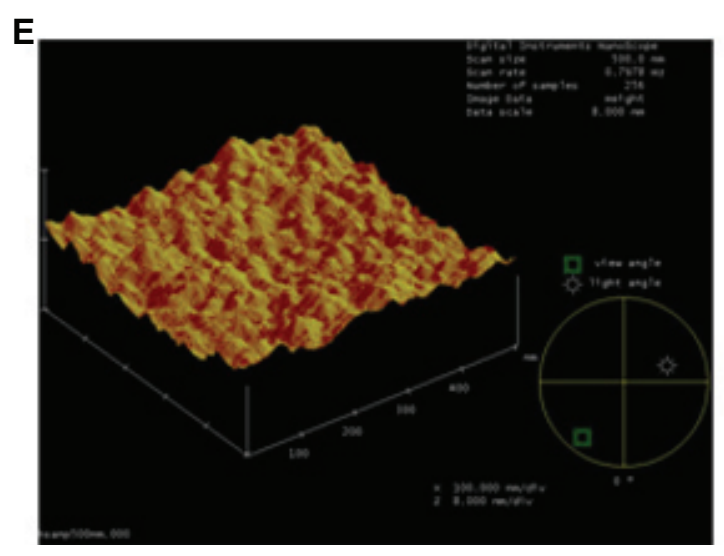

Figure I The TEM, SEM, and AFM micrographs of the nanoparticles illustrate that the particles are properly dispersed, spherically-shaped, and have smooth surface characteristics. A, B, and C TEM images for the nanoparticles crosslinked with $40 \mu \mathrm{L}$ of $5 \%$ (w/v) glutaraldehyde, $200 \mathrm{kV}$ resolution. A) TEM image of the nanoparticles before ultrasonication which indicates that before ultrasonication the nanoparticles form clusters and are not properly dispersed. Bar, $500 \mathrm{~nm}$. B) TEM image of the nanoparticles after ultrasonication for 15 minutes. Here it is demonstrated how ultrasonication assists in separating out the particles more uniformly and the particles are properly dispersed. Bar, $100 \mathrm{~nm}$. C) TEM image of the nanoparticles after magnification. Bar, $100 \mathrm{~nm}$. D) SEM image for the nanoparticles crosslinked with $40 \mu \mathrm{L}$ of $5 \%(w / v)$ glutaraldehyde which demonstrates the smooth surface characteristics of the nanoparticles, $2 \mathrm{kV}$ resolution. Bar, I $\mu \mathrm{m}$. E) Three-dimensional AFM image of the nanoparticles. Bar, $300 \mathrm{~nm}$.

Abbreviations: TEM, transmission electron microscopy; SEM, scanning electron microscopy; AFM, atomic force microscopy.

HUVECs; $40 \mu \mathrm{L}$ of $5 \%$ (w/v) glutaraldehyde was chosen as the optimal concentration for the nanoparticle preparation which resulted in the formation of stable and uniform particles suitable for protein delivery. It should be noted that, in the future, further research might be necessary to replace the application of glutaraldehyde with more biocompatible polymers, but for this study, nanoparticles crosslinked with glutaraldehyde loaded with human angiopoietin-1 and human VEGF were studied further to investigate if the bioactivity of the proteins was maintained. 


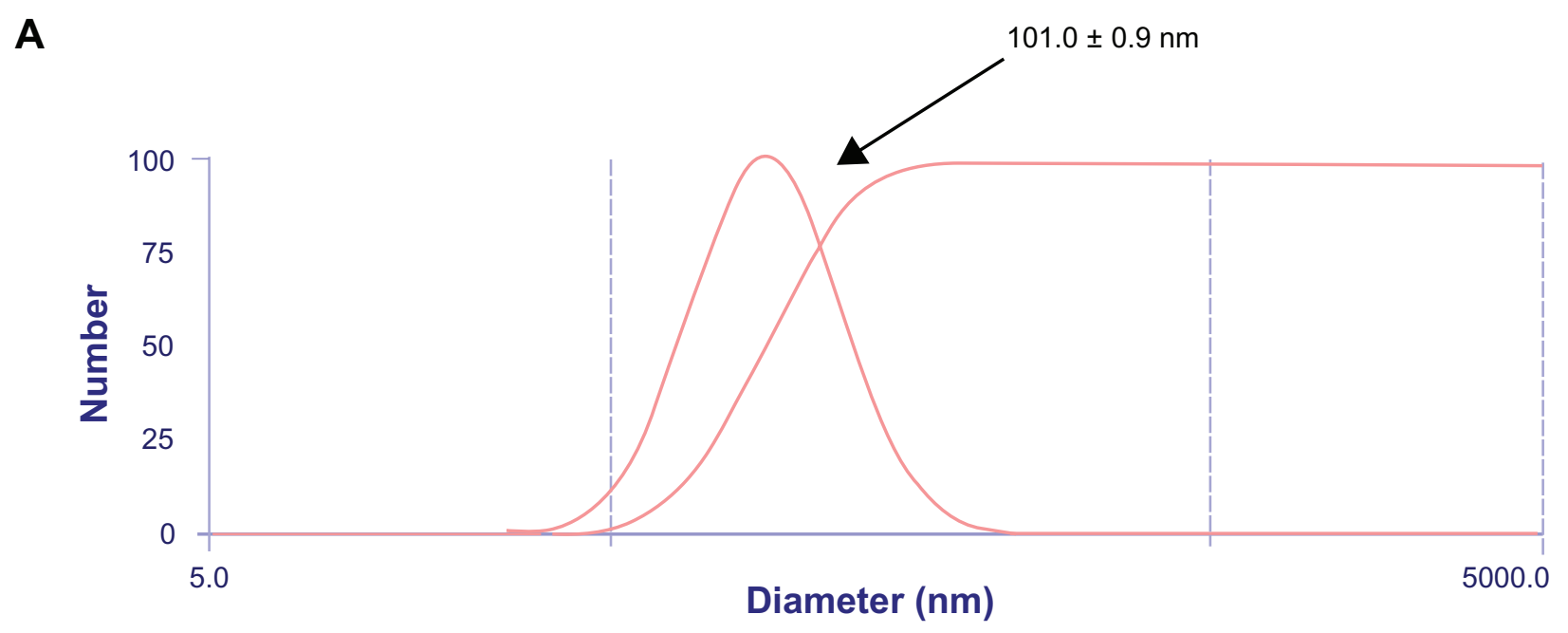

\section{Lognormal distribution}

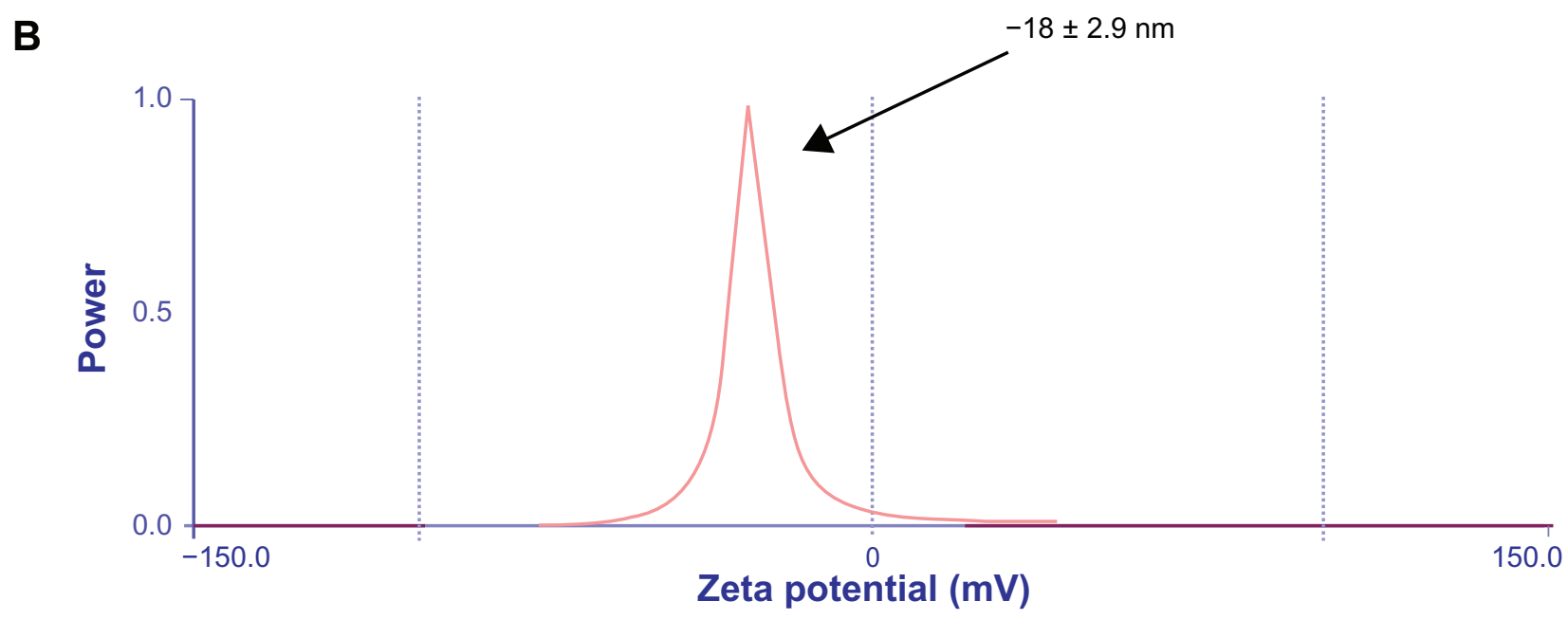

Figure 2 Zeta potential and particle sizer. A) The nanoparticles were prepared by adjusting the $\mathrm{pH}$ of the human serum albumin solution to 8.0 and controlling the amount of coacervation agent to form nanoparticles of size approximately $101.0 \pm 0.9 \mathrm{~nm}$. B) The protein nanoparticles were negatively charged and the zeta potential was $-18 \pm 2.9 \mathrm{mV}$ at $\mathrm{pH}$ 7.0. The zeta potential of the glutaraldehyde crosslinked nanoparticles decreases when the concentration of glutaraldehyde is increased. Zeta potential measurements were performed in phosphate buffer at $\mathrm{pH} 7.0$ because $\mathrm{pH}$ and ionic strength of the dilution medium affects the magnitude of the zeta potential. The polydispersity index was found to be 0.3 .

\section{Encapsulation efficiency and release kinetics profile of proteins coencapsulated in nanoparticles}

It has been shown that coating the nanoparticles with a crosslinking agent increases the encapsulation efficiency, reduces the initial burst release, and extends the protein release period to a slower more efficient release..$^{44}$ In our studies, $40 \mu \mathrm{L}$ of $5 \%$ glutaraldehyde was taken as the optimal amount because the crosslinking agent producing stable nanoparticles with a reduced initial burst release and slower and steady extended-release profiles for both human angiopoietin-1 and human VEGF. The encapsulation efficiency of human angiopoietin-1 and human VEGF during nanoparticle fabrication was $49 \%$ and $55 \%$, respectively. Cumulative release kinetics studies were conducted over two weeks to determine the release of human angiopoietin-1 and human VEGF from the nanoparticles in the culture medium. The release kinetics profiles of both the proteins from the nanoparticles are illustrated in Figure 4. A burst release of both the proteins was observed within the initial two days followed by a lower steady release phase. The burst release amounts for human angiopoietin-1 and human VEGF were approximately $617 \pm 100 \mathrm{ng}$ and $88 \pm 10 \mathrm{ng}$, respectively, with lower steady release amounts of approximately $171.5 \mathrm{ng}$ and $13.75 \mathrm{ng}$ for 


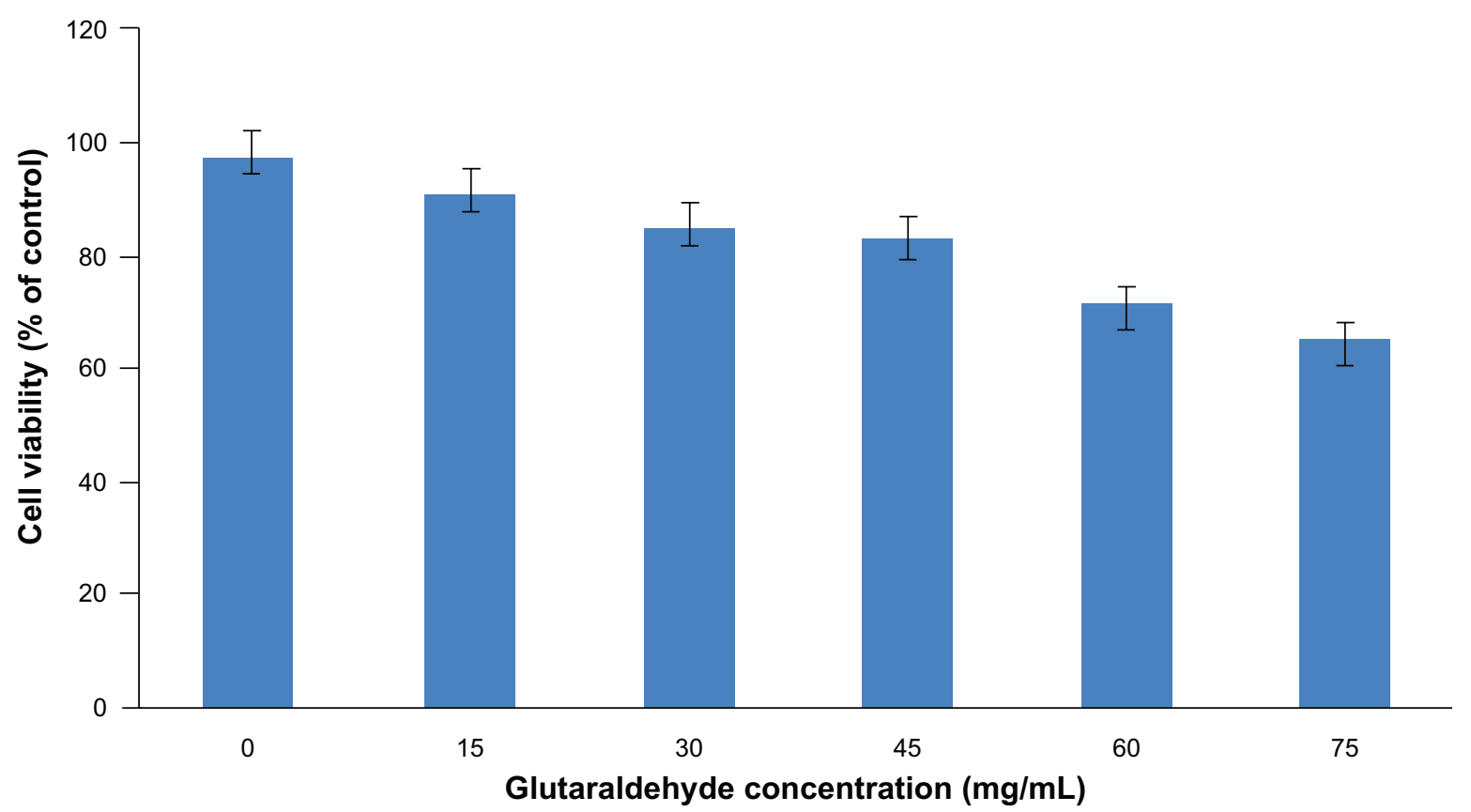

Figure 3 The cytotoxicity of the blank nanoparticles crosslinked with a series of glutaraldehyde concentrations was studied by incubating HUVECs for 96 hours with the nanoparticles. Percent cell viability over initial number of HUVECs treated with nanoparticles for up to 96 hours is shown. MTS assay was used to determine the cell viability after exposure to the nanoparticles. Nanoparticles without glutaraldehyde coating showed a cell viability of above $90 \%$ after 96 hours. Increasing the amount of glutaraldehyde in the particle preparation increased the cytotoxicity of the nanoparticles to the seeded HUVECs.

Abbreviation: HUVECs, human vascular enthothelial cells.

human angiopoietin-1 and human VEGF, respectively. At the end of the 2-week incubation period, it was observed that $49 \%$ of human angiopoietin- 1 and $59 \%$ of human VEGF had been released from the nanoparticles. The cumulative release amounts for human angiopoietin-1 and human VEGF on day 14 were $1680.7 \pm 150 \mathrm{ng}$ and $162.25 \pm 17 \mathrm{ng}$, respectively.

\section{Retention of bioactivity of released human angiopoietin-I and human VEGF on HUVECs}

Human VEGF is an endothelial cell-specific mitogen, which enhances vascular permeability, induces endothelial cell proliferation, and stimulates angiogenesis in vivo. ${ }^{7-14}$ However, as discussed earlier, there has been debate over the role of human angiopoietin-1 as an endothelial cell mitogen. While some studies have demonstrated human angiopoietin- 1 to be a potent mitogen of endothelial cells, ${ }^{23}$ others have pointed out that human angiopoietin-1 either failed to induce proliferation ${ }^{24}$ or did not cause a significant increase in proliferation. ${ }^{24}$ Our results indicate that the human VEGF in combination with human angiopoietin-1 released from the nanoparticles in fact augments HUVEC proliferation significantly, which could enable the potential application of this delivery system for therapeutic angiogenesis.
The bioactivity of the human VEGF, human angiopoietin-1, and bovine serum albumin in media released from the nanoparticles was evaluated in vitro by observing the proliferative capacity of the HUVECs. The CellTiter 96 AQueous Non-Radioactive Cell Proliferation MTS Assay kit was used to assess the proliferation of the HUVECs treated with nanoparticle supernatant. The results were illustrated as the percent increase in cell proliferation relative to the unstimulated control. As shown in Figure 5, the least cell proliferation occurs with nanoparticle supernatant containing human angiopoietin-1 (VEGF antibody added), moderate proliferation with nanoparticle supernatant containing human VEGF (angiopoietin-1 antibody added) and, finally, the highest proliferation is observed in the case of the nanoparticle supernatant containing both human VEGF and human angiopoietin-1. As expected, the control nanoparticle supernatant containing bovine serum albumin produced negligible results. The effect of supernatant containing angiopoietin-1 on cell proliferation is relatively low compared with human VEGF, even though 10 times the amount of human VEGF was used for human angiopoietin-1. In each case, the cell proliferation increases over the two-week incubation period. This is due to the fact that there is more protein amount present in the nanoparticle supernatant as the days increase. The highest cell proliferation was 
A

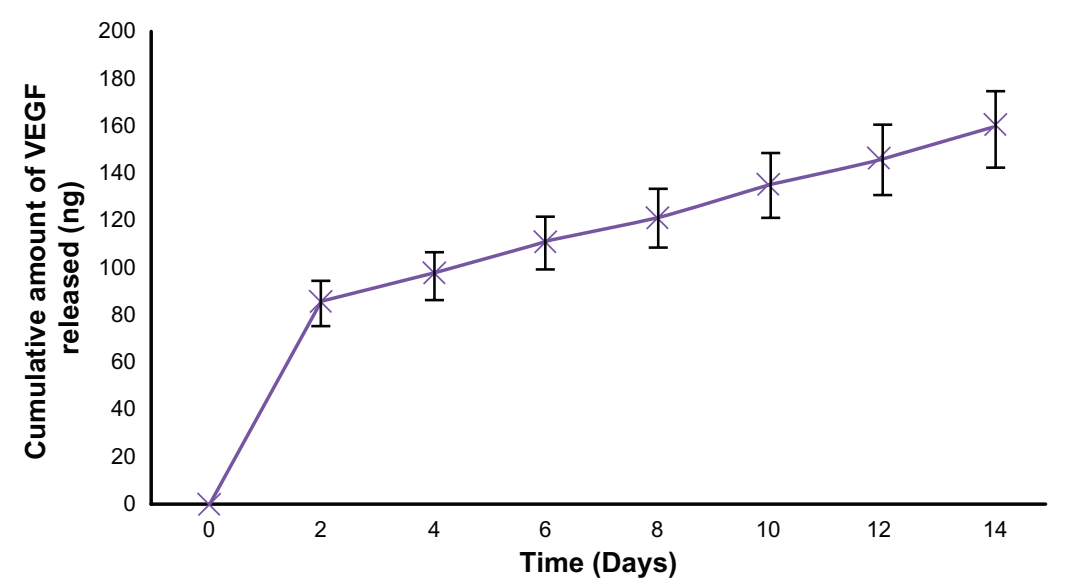

B

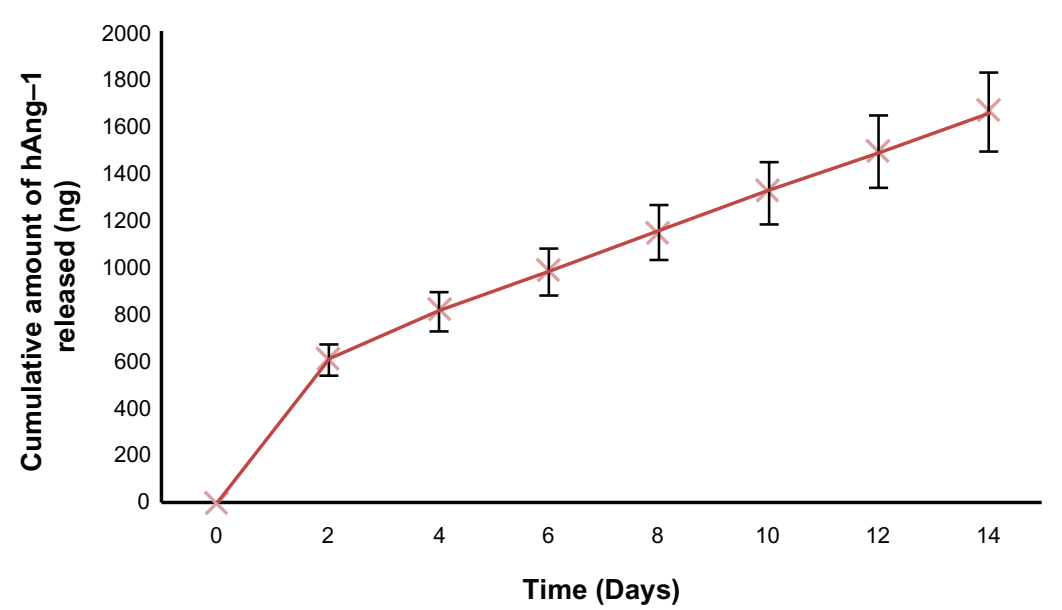

Figure 4 NPs sustain in-vitro protein release. A and B Indicate the cumulative amount of hAng-I and hVEGF released from the NPs over a time period of two weeks. At the end of the two week incubation period it was observed that $49 \%$ of hAng-I and $59 \%$ of hVEGF had been released from the NPs.

observed for nanoparticle supernatant containing both human angiopoietin-1 and human VEGF, which was $89.62 \%$, using nanoparticle supernatant containing human VEGF (angiopoietin-1 antibody added) the proliferation was $67.79 \%$, and using nanoparticle supernatant containing human angiopoietin-1 (VEGF antibody added) the proliferation was 5.87\%. This shows that using both human angiopoietin-1 and human VEGF together will produce the best results.

\section{Retention of antiapoptotic activity of released human angiopoietin-I and human VEGF on HUVECs}

The serum deprivation method was used to induce apoptosis in HUVECs to demonstrate the antiapoptotic effect of both human angiopoietin-1 and human VEGF released from the nanoparticles. Under serum deprivation, the HUVECs seeded in the 96-well plate underwent apoptosis and became detached from the wells. As demonstrated by Kwak et al, human angiopoietin-1 acts as an apoptotic survival factor for endothelial cells. ${ }^{22}$ It was also shown that even when the inhibitory doses of human angiopoietin-1 was 10 times more than human VEGF, both caused identical antiapoptotic effects in HUVECs. In addition, it was also observed that during serum starvation of HUVECs, the antiapoptotic effect of human angiopoietin-1 was significantly increased when human VEGF was added, leading to a combined apoptotic inhibitory effect.

In our study, human angiopoietin-1 and human VEGF were loaded into nanoparticles and the combined antiapoptotic effect of the proteins on the seeded HUVECs was demonstrated. It has been highlighted already that, due to their very limited in vivo half-lives, the proteins have to be administered through multiple injections so as to achieve the desired therapeutic effect. Moreover, these macromolecules 


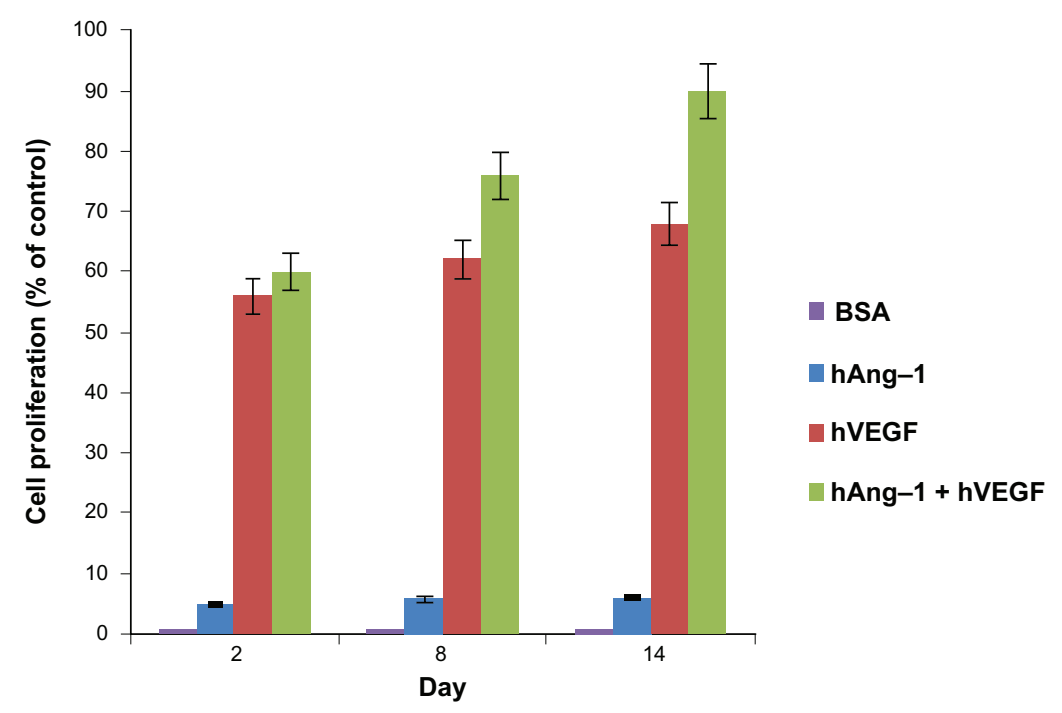

Figure 5 Bioactivity of human angiopoietin-I and human VEGF loaded in nanoparticles. The proliferation of HUVECs in response to the nanoparticle supernatant was observed. HUVECS were seeded in a 96-well plate and the endothelial cell medium was replaced with nanoparticle supernatant with human VEGF antibody, nanoparticle supernatant with human angiopoietin-I antibody, nanoparticle supernatant containing both human angiopoietin-I and human VEGF, nanoparticle supernatant containing bovine serum albumin and endothelial cell medium (with $5 \%$ fetal bovine albumin) as the controls for 96 hours. The results were illustrated as the percent increase in cell proliferation relative to the unstimulated control. Least cell proliferation is observed with human angiopoietin-I and maximum proliferation is observed in supernatant with a combination of both human angiopoietin-I and human VEGF. The supernatant with bovine serum albumin showed a negligible effect as expected. An increasing cell proliferation is observed over the two-week incubation period.

Abbreviations: VEGF, vascular endothelial growth factor; HUVECs, human vascular endothelial cells.

have high molecular weights, which leads to low bioavailability, high aqueous solubility, and an inability to diffuse through biological membranes. ${ }^{29,30}$ The use of nanoparticles for the delivery of these macromolecules, which are in fact very unstable, could aid in protecting them from degradation in the biological environment of the organism. The HUVECs were then seeded and $0.1 \mathrm{~mL}$ of nanoparticle supernatant from days 2, 8, and 14 . Nanoparticle supernatant containing bovine serum albumin and serum-free media without addition of human VEGF and human angiopoietin-1 taken as controls were added to the well and incubated for 96 hours. As shown in Figure 6, the HUVECs with serum-free control media and nanoparticle supernatant containing bovine serum albumin always showed a percent apoptosis above $90 \%$. The release kinetics show that there is an increase in the cumulative amount of proteins released from the nanoparticles. In the study, $0.4 \mathrm{~mL}$ solution was taken from the nanoparticle supernatant and then replaced with serum-free media on the

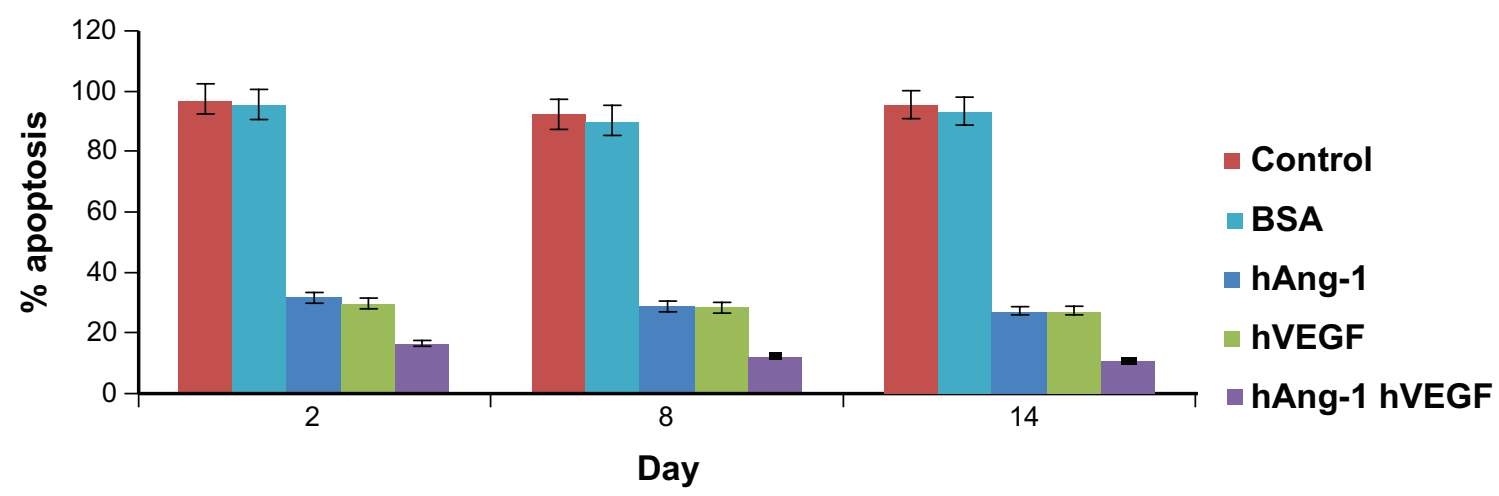

Figure 6 Human angiopoietin-I and human VEGF were loaded into nanoparticles and the combined antiapoptotic effect of the proteins on the seeded HUVECs was demonstrated. HUVECs treated with serum-free control media without addition of human VEGF and human angiopoietin-I proteins, always showed a percent apoptosis above $90 \%$. The release kinetics shows that there is an increase in the cumulative amount of proteins released from the nanoparticles. The percent apoptosis due to nanoparticle supernatant containing human angiopoietin-I (human VEGF antibody added) reduced from $31.5 \%$ to $27.06 \%$ for day 2 to day 14 . Similarly, percent apoptosis due to nanoparticle supernatant containing human VEGF (human angiopoietin-I antibody added) reduced from $29.6 \%$ to $27.74 \%$ for day 2 to day I4. The combined antiapoptotic effect of the nanoparticle supernatant containing human angiopoietin-I and human VEGF decreased from I6.44\% to $10.42 \%$ at day 2 to day 14 . Thus, in comparison with the control, cell apoptosis decreased dramatically (almost by 50\%) with the application of supernatant from nanoparticles loaded with both the proteins.

Abbreviations: VEGF, vascular endothelial growth factor; HUVECs, human vascular endothelial cells. 
A

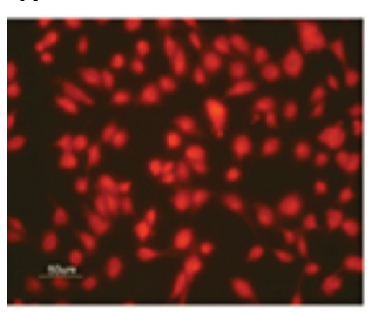

B

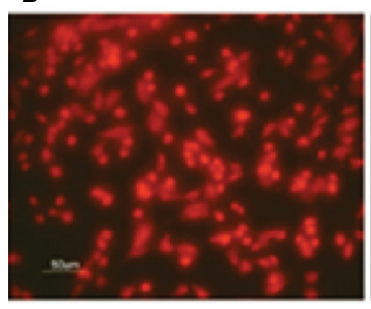

C

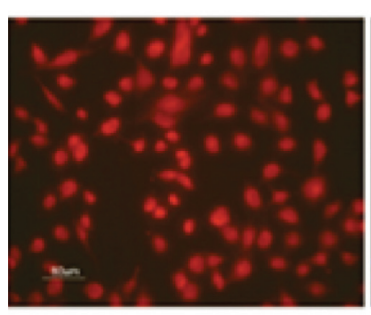

D

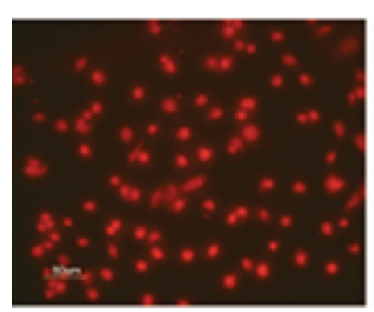

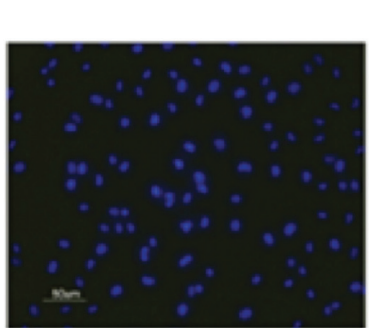

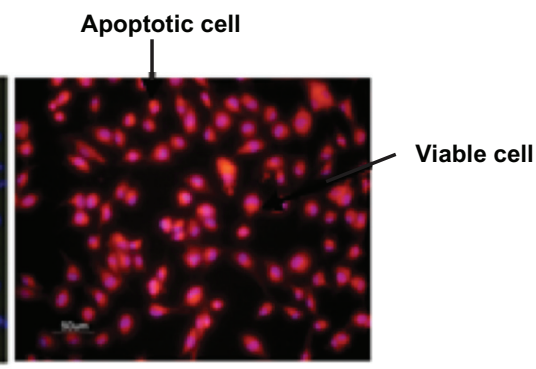

Apoptotic cell
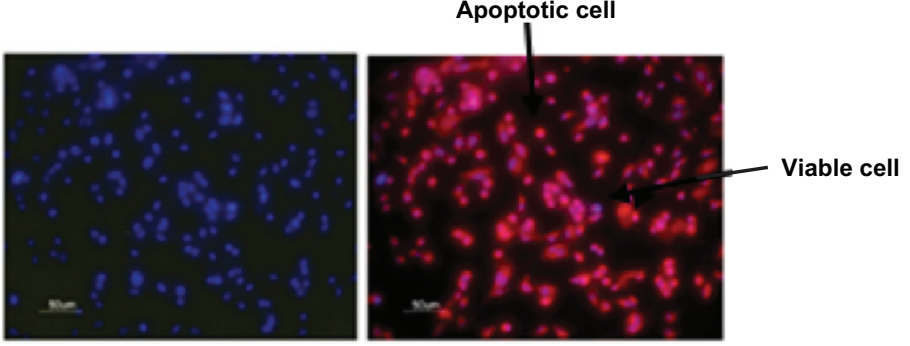

Apoptotic cell
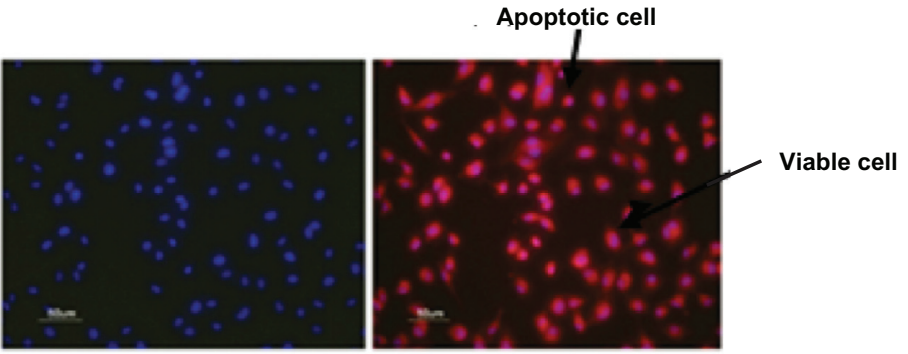

Apoptotic cell

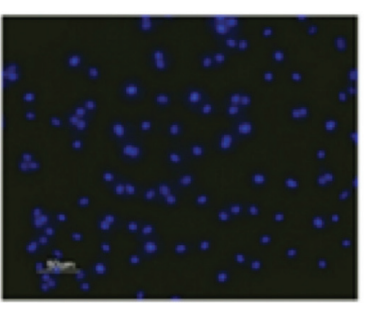

Viable cell

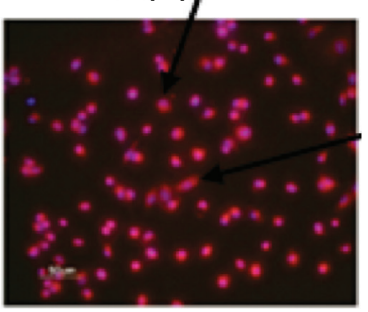

Figure 7 Fluorescent microscope images showing antiapoptotic effect of human angiopoietin-I and human VEGF on HUVECs at day I4. Bar, $50 \mu \mathrm{m}$. It was observed that on day 14, the proteins coencapsulated in the nanoparticles significantly decreased HUVEC apoptosis compared with the control, as well as the individual proteins. Human vascular endothelial cells were seeded onto a 96 -well plate at a cell density of $2 \times 10^{4}$ cells per well. The medium was then replaced with 0.1 mL of A) nanoparticle supernatant, B) nanoparticle supernatant with excess human VEGF antibody, C) nanoparticle supernatant with excess human angiopoietin-I antibody and incubated for 96 hours. D) Control cultures received the same amount of serum-free media without addition of human VEGF and human angiopoietin-I proteins. The numbers of cells floating in each well were collected after phosphate-buffered saline washing and counted. The number of apoptotic cells in the adherent cells was then determined after 96 hours using the MitoTracker ${ }^{\circledR}$ Red CMXRos kit and DAPI nucleic acid staining and counted using fluorescence microscopy.

Abbreviations: HUVECs, human vascular endothelial cells; VEGF vascular endothelial growth factor.

indicated days. The amount taken also has increasing protein content as the days increase. Due to this increasing protein presence, the percent cell apoptosis decreases from day 2 to day 14. The percent apoptosis due to nanoparticle supernatant containing human angiopoietin-1 (human VEGF antibody added) reduced from $31.5 \%$ to $27.06 \%$ for day 2 to day 14 . Similarly, percent apoptosis due to nanoparticle supernatant containing human VEGF (human angiopoietin-1 antibody added) reduced from $29.6 \%$ to $27.74 \%$ from day 2 to 14 . The combined antiapoptotic effect of the nanoparticle supernatant containing human angiopoietin-1 and human VEGF decreased from $16.44 \%$ to $10.42 \%$ for day 2 to day 14 . Thus, in comparison with the control, the cell apoptosis decreased dramatically (almost by $50 \%$ ) with the application of supernatant from nanoparticles loaded with both the proteins.

Figure 7 illustrates the antiapoptotic effect of human angiopoietin-1 and human VEGF on HUVECs for day 14. It was observed that, on day 14 , the proteins coencapsulated 
in the nanoparticles significantly decreased HUVEC apoptosis compared with the control, as well as the individual proteins. The HUVECs were seeded onto a 96-well plate at a cell density of $2 \times 10^{4}$ cells per well. After 24 hours, the medium was then replaced with $0.1 \mathrm{~mL}$ of nanoparticle supernatant, nanoparticle supernatant with excess human VEGF antibody, or nanoparticle supernatant with excess human angiopoietin-1 antibody, and incubated for 96 hours as shown in Figures 7A, 7B, and 7C. Control cultures received the same amount of serum-free media without proteins, as shown in Figure 7D.

\section{Conclusion}

In summary, we examined the in vitro effect of application of the angiogenic proteins, human VEGF and human angiopoietin-1, coencapsulated in albumin nanoparticles, on therapeutic angiogenesis. Our results demonstrate that application of a nanoparticle system provided slow, continuous, and extended-release kinetics of the proteins which, in turn, resulted in an augmented combined effect of the released angiogenic proteins on proliferation and antiapoptosis of HUVECs in comparison with the released individual proteins. Future perspectives could involve in vivo studies demonstrating the potential of clinical application of this system towards therapeutic angiogenesis.

\section{Acknowledgments}

This work was supported by a research grant to SP from the Canadian Institute of Health Research. AP acknowledges the financial support of the Natural Sciences and Engineering Research Council, Canada, in the form of the Alexander Graham Bell Canada Graduate Scholarship. SA is supported by the McGill Faculty of Medicine Internal Studentship on the GG Harris Fellowship. The authors thank Dr Xue-Dong Liu of McGill University, Physics Department, for the TEM imaging.

\section{Disclosure}

The authors report no conflicts of interest in this work.

\section{References}

1. Holash J, Wiegand SJ, Yancopoulos GD. New model of tumor angiogenesis: Dynamic balance between vessel regression and growth mediated by angiopoietins and VEGF. Oncogene. 1999;18(38):5356-5362.

2. Isner JM, Asahara T. Angiogenesis and vasculogenesis as therapeutic strategies for postnatal neovascularization. J Clin Invest. 1999;103(9): 1231-1236.

3. Kerr JF, Wyllie AH, Currie AR. Apoptosis: A basic biological phenomenon with wide-ranging implications in tissue kinetics. Br J Cancer. 1972;26(4):239-257.

4. Fujio Y, Walsh K. Akt mediates cytoprotection of endothelial cells by vascular endothelial growth factor in an anchorage-dependent manner. J Biol Chem. 1999;274(23):16349-16354.
5. Gerber HP, Dixit V, Ferrara N. Vascular endothelial growth factor induces expression of the antiapoptotic proteins Bcl-2 and A1 in vascular endothelial cells. J Biol Chem. 1998;273(21):13313-13316.

6. Gerber HP, McMurtrey A, Kowalski J, et al. Vascular endothelial growth factor regulates endothelial cell survival through the phosphatidylinositol 3'-kinase Akt signal transduction pathway - requirement for Flk-1/ KDR activation. J Biol Chem. 1998;273(46):30336-30343.

7. Asahara T, Bauters C, Zheng LP, et al. Synergistic effect of vascular endothelial growth factor and basic fibroblast growth factor on angiogenesis in vivo. Circulation. 1995;92(9 Suppl):II365-II371.

8. Banai S, Jaklitsch MT, Shou M, et al. Angiogenic-induced enhancement of collateral blood flow to ischemic myocardium by vascular endothelial growth factor in dogs. Circulation. 1994;89(5):2183-2189.

9. Bauters C, Asahara T, Zheng LP, et al. Physiological assessment of augmented vascularity induced by VEGF in ischemic rabbit hindlimb. Am J Physiol. 1994;267(4 Pt 2):H1263-H1271.

10. Bauters C, Asahara T, Zheng LP, et al. Site-specific therapeutic angiogenesis after systemic administration of vascular endothelial growth factor. J Vasc Surg. 1995;21(2):314-324.

11. Bauters C, Asahara T, Zheng LP, et al. Recovery of disturbed endothelium-dependent flow in the collateral-perfused rabbit ischemic hindlimb after administration of vascular endothelial growth factor. Circulation. 1995;91(11):2802-2809.

12. Takeshita S, Pu LQ, Stein LA, et al. Intramuscular administration of vascular endothelial growth factor induces dose-dependent collateral artery augmentation in a rabbit model of chronic limb ischemia. Circulation. 1994;90(5 Pt 2):II228-II234.

13. Takeshita S, Rossow ST, Kearney M, et al. Time course of increased cellular proliferation in collateral arteries after administration of vascular endothelial growth factor in a rabbit model of lower limb vascular insufficiency. Am J Pathol. 1995;147(6):1649-1660.

14. Takeshita S, Zheng LP, Brogi E, et al. Therapeutic angiogenesis. A single intraarterial bolus of vascular endothelial growth factor augments revascularization in a rabbit ischemic hind limb model. J Clin Invest. 1994;93(2):662-670.

15. Bates DO, Harper SJ. Regulation of vascular permeability by vascular endothelial growth factors. Vascul Pharmacol. 2002;39(4-5):225-237.

16. Dvorak HF, Nagy JA, Feng D, Brown LF, Dvorak AM. Vascular permeability factor/vascular endothelial growth factor and the significance of microvascular hyperpermeability in angiogenesis. Curr Top Microbiol Immunol. 1999;237:97-132.

17. Lee RJ, Springer ML, Blanco-Bose WE, Shaw R, Ursell PC, Blau HM. VEGF gene delivery to myocardium: Deleterious effects of unregulated expression. Circulation. 2000;102(8):898-901.

18. Gamble JR, Drew J, Trezise L, et al. Angiopoietin-1 is an antipermeability and anti-inflammatory agent in vitro and targets cell junctions. Circ Res. 2000;87(7):603-607.

19. Thurston G, Rudge JS, Ioffe E, et al. Angiopoietin-1 protects the adult vasculature against plasma leakage. Nat Med. 2000;6(4):460-463.

20. Thurston G, Suri C, Smith K, et al. Leakage-resistant blood vessels in mice transgenically overexpressing angiopoietin-1. Science. 1999; 286(5449):2511-2514.

21. Kim I, Kim HG, So JN, Kim JH, Kwak HJ, Koh GY. Angiopoietin-1 regulates endothelial cell survival through the phosphatidylinositol 3'Kinase/Akt signal transduction pathway. Circ Res. 2000;86(1):24-29.

22. Kwak HJ, So JN, Lee SJ, Kim I, Koh GY. Angiopoietin-1 is an apoptosis survival factor for endothelial cells. FEBS Lett. 1999;448(2-3): 249-253.

23. Kanda S, Miyata Y, Mochizuki Y, Matsuyama T, Kanetake H. Angiopoietin 1 is mitogenic for cultured endothelial cells. Cancer Res. 2005;65(15):6820-6827.

24. Hayes AJ, Huang WQ, Mallah J, Yang D, Lippman ME, Li LY. Angiopoietin-1 and its receptor Tie-2 participate in the regulation of capillarylike tubule formation and survival of endothelial cells. Microvasc Res. 1999;58(3): 224-237.

25. Koblizek TI, Weiss C, Yancopoulos GD, Deutsch U, Risau W. Angiopoietin-1 induces sprouting angiogenesis in vitro. Curr Biol. 1998;8(9):529-532. 
26. Cao R, Brakenhielm E, Pawliuk R, et al. Angiogenic synergism, vascular stability and improvement of hind-limb ischemia by a combination of PDGF-BB and FGF-2. Nat Med. 2003;9(5):604-613.

27. Richardson TP, Peters MC, Ennett AB, Mooney DJ. Polymeric system for dual growth factor delivery. Nat Biotechnol. 2001;19(11): 1029-1034.

28. Saif J, Schwarz TM, Chau DY, et al. Combination of injectable multiple growth factor-releasing scaffolds and cell therapy as an advanced modality to enhance tissue neovascularization. Arterioscler Thromb Vasc Biol. 2010;30(10):1897-1904

29. Ravivarapu HB, Burton K, DeLuca PP. Polymer and microsphere blending to alter the release of a peptide from PLGA microspheres. Eur J Pharm Biopharm. 2000;50(2):263-270.

30. Sanders LM. Drug delivery systems and routes of administration of peptide and protein drugs. Eur J Drug Metab Pharmacokinet. 1990;15(2): 95-102.

31. King TW, Patrick CW Jr. Development and in vitro characterization of vascular endothelial growth factor (VEGF)-loaded poly(DL-lacticco-glycolic acid)/poly(ethylene glycol) microspheres using a solid encapsulation/single emulsion/solvent extraction technique. J Biomed Mater Res. 2000;51(3):383-390.

32. Panyam J, Labhasetwar V. Biodegradable nanoparticles for drug and gene delivery to cells and tissue. Adv Drug Deliv Rev. 2003;55(3): 329-347.

33. Kragh-Hansen U. Structure and ligand binding properties of human serum albumin. Dan Med Bull. 1990;37(1):57-84.

34. Kragh-Hansen U, Chuang VT, Otagiri M. Practical aspects of the ligandbinding and enzymatic properties of human serum albumin. Biol Pharm Bull. 2002;25(6):695-704.

35. Gallo GR, Wertheimer AI. An international survey of drug information centers. Drug Inf J. 1985;19(1):57-61.
36. Lin W, Coombes AG, Davies MC, Davis SS, Illum L. Preparation of sub-100 nm human serum albumin nanospheres using a $\mathrm{pH}$-coacervation method. J Drug Target. 1993;1(3):237-243.

37. Weber C, Kreuter J, Langer K. Desolvation process and surface characteristics of HSA-nanoparticles. Int J Pharm. 2000;196(2):197-200.

38. Mo Y, Barnett ME, Takemoto D, Davidson H, Kompella UB. Human serum albumin nanoparticles for efficient delivery of $\mathrm{Cu}, \mathrm{Zn}$ superoxide dismutase gene. Mol Vis. 2007;13:746-757.

39. Sebak S, Mirzaei M, Malhotra M, Kulamarva A, Prakash S. Human serum albumin nanoparticles as an efficient noscapine drug delivery system for potential use in breast cancer: Preparation and in vitro analysis. Int J Nanomedicine. 2010;5:525-532.

40. Adya R, Tan BK, Punn A, Chen J, Randeva HS. Visfatin induces human endothelial VEGF and MMP-2/9 production via MAPK and PI3K/Akt signalling pathways: Novel insights into visfatin-induced angiogenesis. Cardiovasc Res. 2008;78(2):356-365.

41. Afkhami F, DurocherY, Prakash S. Investigation of antiangiogenic tumor therapy potential of microencapsulated HEK293 VEGF165b producing cells. J Biomed Biotechnol. 2010;2010:645610.

42. Milovic-Holm K, Krieghoff E, Jensen K, Will H, Hofmann TG. FLASH links the CD95 signaling pathway to the cell nucleus and nuclear bodies. EMBO J. 2007;26(2):391-401.

43. Lin W, Coombes AG, Garnett MC, et al. Preparation of sterically stabilized human serum albumin nanospheres using a novel DextranoxMPEG crosslinking agent. Pharm Res. 1994;11(11):1588-1592.

44. Zhang S, Wang G, Lin X, et al. Polyethylenimine-coated albumin nanoparticles for BMP-2 delivery. Biotechnol Prog. 2008;24(4):945-956.
International Journal of Nanomedicine

\section{Publish your work in this journal}

The International Journal of Nanomedicine is an international, peerreviewed journal focusing on the application of nanotechnology in diagnostics, therapeutics, and drug delivery systems throughout the biomedical field. This journal is indexed on PubMed Central,

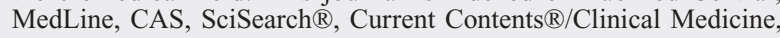

\section{Dovepress}

Journal Citation Reports/Science Edition, EMBase, Scopus and the Elsevier Bibliographic databases. The manuscript management system is completely online and includes a very quick and fair peer-review system, which is all easy to use. Visit http://www.dovepress.com/ testimonials.php to read real quotes from published authors. 